\title{
Measurement of mechanical properties of snow for simulation of skiing
}

\author{
Martin MÖSSNER, ${ }^{1}$ Gerhard INNERHOFER, ${ }^{1}$ Kurt SCHINDELWIG, ${ }^{2}$ Peter KAPS, ${ }^{3}$ \\ Herwig SCHRETTER, ${ }^{4}$ Werner NACHBAUER ${ }^{2}$
}

\author{
${ }^{1}$ Centre of Technology of Ski and Alpine Sport, University of Innsbruck, Innsbruck, Austria \\ E-mail: martin.moessner@uibk.ac.at \\ ${ }^{2}$ Department of Sport Science, University of Innsbruck, Innsbruck, Austria \\ ${ }^{3}$ Department of Engineering Mathematics, University of Innsbruck, Innsbruck, Austria \\ ${ }^{4}$ HTM Tyrolia, Schwechat, Austria
}

\begin{abstract}
In the simulation of skiing the force between ski and snow is a decisive factor. We decompose the reaction force into a penetration force normal to the snow surface, a shear force and friction. Two portable measurement devices were developed to study the penetration and shear forces for compacted snow on groomed ski slopes. The penetration force was assessed by measuring the penetration depth of a ski-tool loaded normal to the snow surface. For the shear force the tangential load was measured when the snow began to fail. Overall 236 penetration and 108 shear experiments were conducted on different types of snow. The penetration force was proportional to the volume of snow displaced by the ski-tool. The failure shear force was proportional to the penetration depth multiplied by the length of the tool. The constants of proportionality, $H_{\mathrm{V}}$ and $S_{\mathrm{f}}$, are material parameters of snow. The snow hardness, $H_{\mathrm{V}}$, varied between 0.04 and $90 \mathrm{~N} \mathrm{~mm}^{-3}$ and the failure shear stress, $S_{\mathrm{f}}$, between 0.04 and $0.40 \mathrm{~N} \mathrm{~mm}^{-2}$. In another investigation, skiing turns were simulated using the presented snow reaction forces. Maximum deviations between computed and real trajectories were $<1 \%$ of the overall length of the runs.
\end{abstract}

\section{INTRODUCTION}

Fresh fallen snow has a low density, $<100 \mathrm{~kg} \mathrm{~m}^{-3}$. The snow is a mixture of solid snow crystals, liquid water and gaseous air. Over time it is compacted by wind. Snow crystals are sintered by daily temperature variations. The snow loses most of its gaseous and liquid content and, because of this, snow densities rise to $100-500 \mathrm{~kg} \mathrm{~m}^{-3}$. After a long time, snow converts to firn (500-800 $\mathrm{kg} \mathrm{m}^{-3}$ ) and, under the load of newer snow, it even transforms to ice $\left(917 \mathrm{~kg} \mathrm{~m}^{-3}\right)$. Accordingly, snow exists in manifold states (Fierz and others, 2009) and various targets are chosen for snow investigation (snow streets, avalanches, glaciers, etc.). Reviews of physical properties of snow and ice have been presented by Mellor (1975) and Shapiro and others (1997). Here we consider snow on groomed ski slopes, where it is mechanically compacted and homogenized. Because of daily temperature variations, snow particles are sintered to a great extent. On ski slopes Nachbauer and others (1996) observed snow densities between 330 and $490 \mathrm{~kg} \mathrm{~m}^{-3}$, while Federolf and others (2006) reported values between 430 and $660 \mathrm{~kg} \mathrm{~m}^{-3}$.

In skiing simulations the snow reaction force produced by the snow is a decisive factor. Small variations in the snow properties may cause large effects in the turn radius of a skier (Mössner and others, 2009). The side guidance is affected by the shear strength of the snow, and, because the shear force is proportional to the penetration depth, also by the penetration force. We decompose the overall reaction force into (1) the force against penetration normal to the undisturbed snow surface, (2) the force against shearing snow transverse to the ski and (3) the frictional force between ski and snow.

In a controlled laboratory setting, Theile and others (2009) investigated, in a uniaxial loading experiment, both the nonlinear elastic loading behavior of snow and its hypoplastic unloading pattern. Johnson and Schneebeli (1999) related the overall reaction force to micromechanical parameters of the snow. In particular, they modeled the penetration force as $F=N f$, with $N$ the number of bonds between the snow particles and $f$ the contribution of each element. For the shear force of snow the shear modulus (Camponovo and Schweizer, 2001; Nakamura and others, 2010) and the failure shear force (Brun and Rey, 1987; Domine and others, 2011) have been determined. However, the focus of those studies was naturally packed snow with densities of $100-500 \mathrm{~kg} \mathrm{~m}^{-3}$.

Lieu and Mote (1984) performed machining experiments on ice and gave an empirical formula for the dynamic shear force of ice. For snow they proposed a scale factor of 0.02 and used the data to simulate a turn with a point-mass for the skier and a single elastic beam for the skis (Lieu and Mote, 1985; Mote and Renshaw, 1991). Brown and Outwater (1989) performed dynamic shear experiments with a handheld tool and advised on how to apply these data in simulations (Brown, 2009). For shearing, machining theory was employed. There the cutting force depends on the edge angle (Eqn (10)). Nordt and others (1999a,b) developed a simulation model with a multi-segment ski model. The snow reaction force (Nordt and others, 1999b, eqn (2)) was modeled by the shear force given by Brown and Outwater (1989) and was applied normal to the ski base. Hirano and Tada (1996) and Tada and Hirano (1999, 2002) performed shear experiments on synthetic snow and gave regression equations for oblique cutting. They computed the penetration depth from a quadratic force/penetration relation. In a simulation they showed that the shear forces of their measurements caused the ski to turn in a similar way to 
real ski turns. Federolf and others (2006) developed a device to measure the deformation of snow normal to the running surface of a ski and used the data in an inverse dynamic investigation on skiing (Federolf and others, 2010a,b). Although these investigations provide new insights, they do not give both normal and transverse components of the snow reaction force for a ski. Because compaction and shearing constitute different physical processes, they should be modeled by different force laws.

The aim of this study is to measure the normal and transverse reaction forces of a ski on the compacted snow of ski slopes, and measurement devices were developed to use in field experiments. Models for the normal and transverse reaction force of snow, that could be used to simulate skiing, were derived and related material parameters of snow were determined.

\section{METHOD}

Two measurement devices were developed, one for the penetration force normal to the undisturbed snow surface of a hill and one for the failure shear force tangential to the snow surface. The failure shear force is the load when shearing starts. We did not investigate the case when shearing continues (referred to as dynamic shearing in this paper). The failure shear force relates to the dynamic shear force in an analogous way to the relationship between the static friction force and the kinetic friction force.

\section{Penetration force}

\section{Data collection}

The measurement device for the penetration force consisted of a vertical pole with a ski-tool at its lower end and a tray to hold weight discs at its upper end (Fig. 1). The pole was loaded on top with weight discs and moved up and down along a vertical guide. The ski-tool was made of a small piece of a real ski (length $L=200 \mathrm{~mm}$, width $W=62 \mathrm{~mm}$ ) and was mounted with a prescribed edge angle. The penetration of the ski-tool into the snow was measured using a mechanical gauge with a precision of $0.01 \mathrm{~mm}$.

The basal plate of the measurement device was not anchored in the snow. The only forces between the apparatus and snow were the loads of the weights acting in the vertical direction, the snow force acting against the penetration, and the friction and shear resistance along the plate and the skitool. The component of the snow reaction force normal to the undisturbed snow surface of the hill is referred to as the penetration force of the snow. Since friction along the plate and shear forces from the tool were the only forces that kept the apparatus in place, the experiment had to be done on a flat part of the slope. Consequently, there was, at maximum, a small angle between the normal of the snow surface and the vertical axis.

For measurements, the edge angle of the ski-tool was adjusted to a prescribed value and the pole with the tool was positioned on the snow surface. A series of weight discs were placed on top of the device, and the penetration depth with respect to the loaded weight was recorded. At maximum, weights to a total mass of $50 \mathrm{~kg}$ were applied, to cover typical loads in skiing. The discs were weighted in the laboratory using a force plate (Kistler Holding AG, Winterthur, Switzerland). To avoid force peaks, damping materials were glued onto the discs and the weights were laid down gently. During the measurement, we had to check

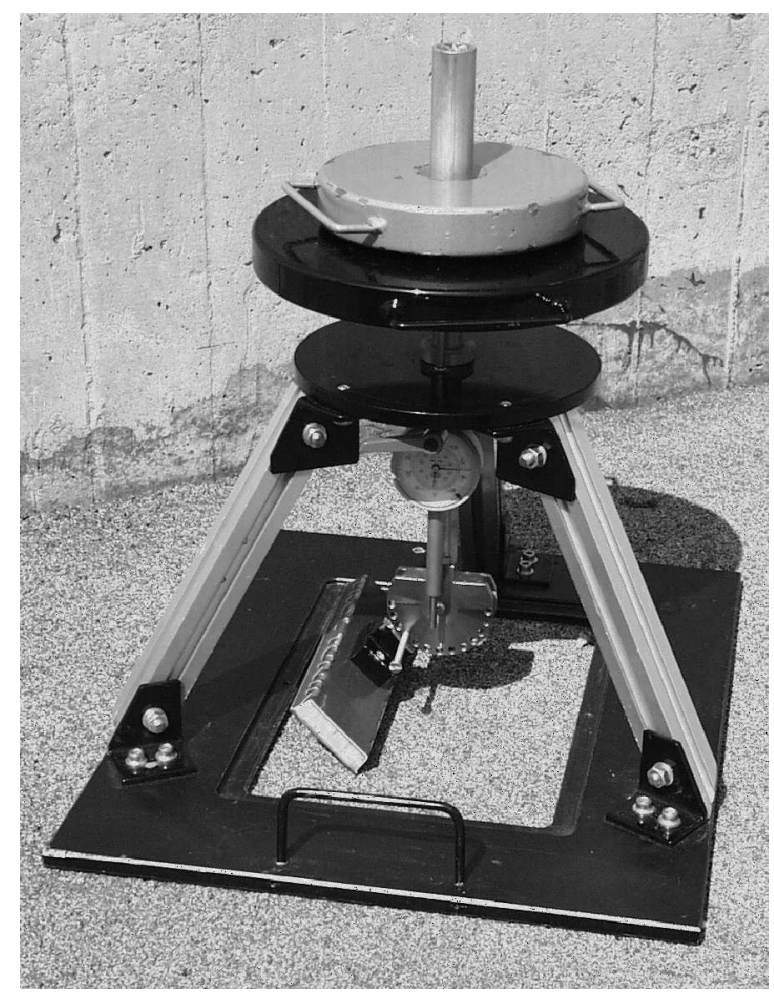

Fig. 1. Measurement device for penetration force.

whether the penetration depth remained constant. In some cases the penetration depth constantly and slowly increased with time. This happened with soft snow, when the whole apparatus moved sideways, and with hard snow, when the apparatus tilted over. In such cases, and when the snow surface crushed, the series was canceled. In the following, each series is referred to as one penetration experiment. A total of 236 experiments were performed, with prescribed edge angles between 0 and $60^{\circ}$, loads between 12 and $492 \mathrm{~N}$, and on different types of snow.

In this work we considered compacted snow of groomed ski slopes in the European Alps. To classify the snow, penetration hardness, $H_{p}$, using a snow penetrometer (Smithers Rapra, Ltd, Shawbury, UK), snow density, $\rho$, air and snow temperature, as well as date and time were recorded. The snow penetrometer was a tool with a drop cone. In the measurement a cone (mass $0.22 \mathrm{~kg}$ ) fell from a height of $21.9 \mathrm{~cm}$ to the snow surface, and hardness, $H_{\mathrm{p}}$, was given by the mean value of the cone's penetration depth in three repeats of the experiment (Nachbauer and others, 1996). Snow density, $\rho$, was obtained using a cylindrical snow cutter (Conger and McClung, 2009) with a volume of $50 \mathrm{~cm}^{3}$.

\section{Data processing}

Each of the $m=236$ measurements consisted of a series of data $e_{j}, F_{j}, j=1, \ldots, 7$ of penetration depths, $e_{j}$, for the edge of the ski-tool and loads, $F_{j}$, acting along the vertical axis. Further data were the edge angle of the ski-tool, $\vartheta$, and the snow properties (penetration hardness, $H_{p}$, snow density, $\rho$, etc.). Because of the frictionless guide of the pole, the vertical component of the load of the snow via the ski-tool was given by the weight of discs, pole and ski-tool. Since the measurement device had to be positioned on a flat part of the slope, the vertical load approximately equaled the integral of the normal component of the snow reaction stress 


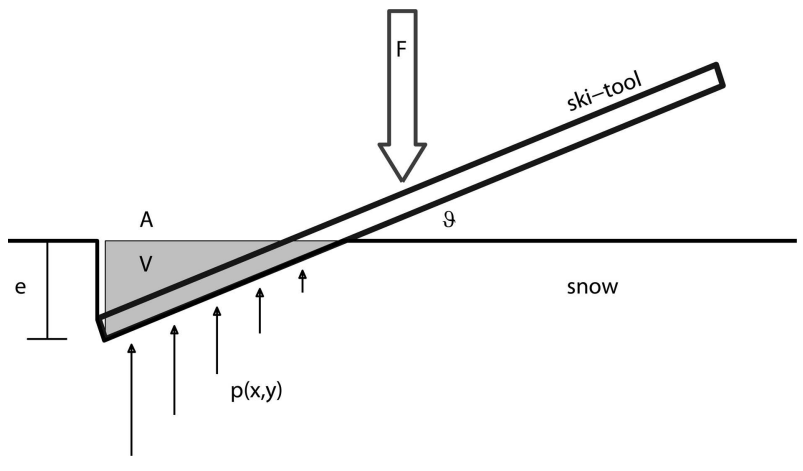

Fig. 2. Measurement of the penetration force. F: applied load; $p(x, y)$ : vertical component of snow reaction stress; $e$ : penetration depth of the ski edge; $\vartheta$ : edge angle; $A$ : projected contact area of the ski-tool to the snow surface; $V$ : volume of snow displaced by the ski-tool.

(Fig. 2). Hence, we do not distinguish between the vertical and the normal component of the load.

We model the normal component of the snow reaction force, but not the components parallel to the snow surface. The reaction force is proportional to a quantity that describes the resistance of snow against penetration. In materials science, such a resistance is quantified by the hardness of the material. Hardness is defined either as reaction force per penetration depth or by reaction force per contact area or by reaction force per volume change. Thus, we define the snow hardness as

$$
H_{\mathrm{e}}=\frac{F_{7}}{e_{7}} \quad \text { or } \quad H_{\mathrm{A}}=\frac{F_{7}}{A_{7}} \quad \text { or } \quad H_{\mathrm{V}}=\frac{F_{7}}{V_{7}} .
$$

The definition of snow hardness needs to be independent of the applied load. The data analysis shows that $H_{V}$ is the appropriate definition. We use the values for the largest load, because these data are least influenced by measurement errors. $F$ is the load that equals the normal component of the snow reaction force, $A$ is the projection of the contact area of the ski-tool to the snow surface and $V$ is the displaced volume of snow without the contribution from the side wall. Thus, we have

$$
A=\frac{L e}{\tan \vartheta} \quad \text { and } \quad V=\frac{L e^{2}}{2 \tan \vartheta}
$$

for the edged ski-tool $(\vartheta>0)$ and

$$
A=L W \quad \text { and } \quad V=L W e
$$

if the ski-tool is flat $(\vartheta=0)$.

In the measurement the snow surface is a horizontal plane. We define a Cartesian coordinate system on the snow surface. The penetration depth of a point, $(x, y)$, on the snow surface caused by the ski-base is given by $\varepsilon(x, y)$, the penetration depth of the ski edge is $e$ and the base is inclined by the edge angle, $\vartheta$. The normal component of the contact stress, $p$, is then modeled as a bilinear polynomial in $\varepsilon$ and $\vartheta$ :

$$
p(x, y)=H \cdot(a(\vartheta)+b(\vartheta) \varepsilon(x, y)),
$$

with $a(\vartheta)=a_{0}+a_{1} \vartheta, b(\vartheta)=b_{0}+b_{1} \vartheta$ and $H=H_{\mathrm{e}}, H_{\mathrm{A}}$ or $H_{V}$. Consequently, the component of the snow reaction force normal to the snow surface is given by

$$
\begin{aligned}
F_{\mathrm{n}} & =\int p(x, y) \mathrm{d} A=\frac{H L}{\tan \vartheta}\left(a(\vartheta) e+b(\vartheta) \frac{e^{2}}{2}\right) \\
& =H \cdot(a(\vartheta) A+b(\vartheta) V) .
\end{aligned}
$$

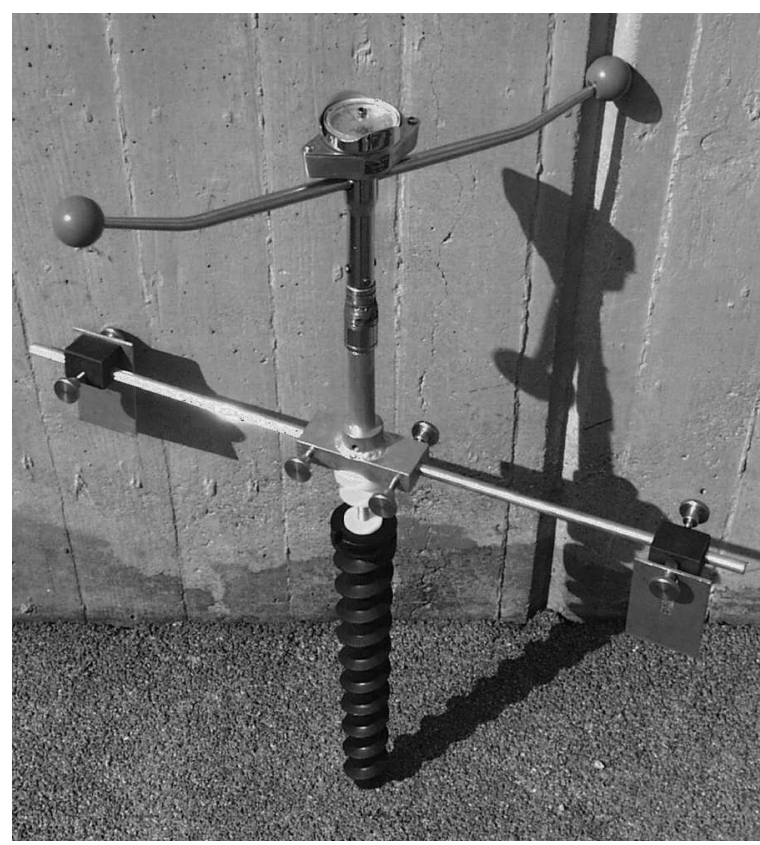

Fig. 3. Measurement device for the failure shear force of snow.

The snow reaction force increases with penetration depth. Thus, we require $a(\vartheta) \geq 0$ and $b(\vartheta) \geq 0$. The coefficients of the polynomials, $a$ and $b$, are computed by (constrained) least-squares fitting (Gill and others, 1995). The fitting is done for the whole entity of data and not for each measurement separately:

$$
\begin{gathered}
\sum_{i=1}^{m} \sum_{j=1}^{7}\left|r_{i, j}\right|^{2} \longrightarrow \min \\
r_{i, j}=H_{i} \cdot\left(a\left(\vartheta_{i}\right) A\left(e_{i, j}, \vartheta_{i}\right)+b\left(\vartheta_{i}\right) V\left(e_{i, j}, \vartheta_{i}\right)\right)-F_{i, j} \\
a\left(\vartheta_{i}\right) \geq 0, \quad b\left(\vartheta_{i}\right) \geq 0,
\end{gathered}
$$

with $A(.,$.$) and V(.,$.$) given by Eqn (2) or (3).$

\section{Failure shear force}

\section{Data collection}

The measurement device for the failure shear force of snow was fabricated from a vertical pole with two lever arms and plates at its ends (Fig. 3). At the top of the pole a moment gauge was mounted to measure the applied moment. In the experiment the pole was anchored normal to the snow surface by a slalom pole anchorage. The plates were attached at a prescribed distance and with a prescribed edge angle. Then the plates were positioned in the snow (Fig. 4) and a moment was manually applied to the pole until the plates started to shear off snow. The corresponding force is called the failure shear force of snow. With this device it was not possible to measure the dynamic shear force during the movement of the plates. Penetration depth, lever arm, edge angles of the plates and moment were recorded. A total of 108 experiments were performed, with various types of snow. As with the penetration measurements, snow parameters and ambient conditions were recorded.

\section{Data processing}

Because the anchorage fixed the pole quite well, the measurements were done with only one plate. Let $e$ be the penetration depth of the plate, $r$ the lever arm to the middle of the plate, $\vartheta$ the edge angle and $M$ the applied moment. 


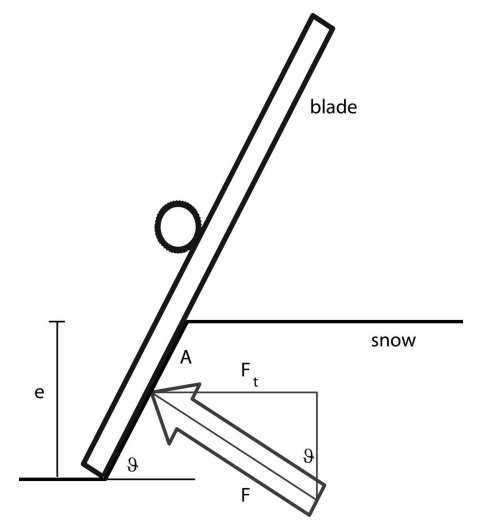

Fig. 4. Measurement of the failure shear force of snow. $F$ : total snow reaction force; $F_{\mathrm{t}}$ : failure shear force of snow (equal to the component of the total snow reaction force parallel to the snow surface); e: penetration depth of the blade; $\vartheta$ : edge angle; $A$ : contact area between blade and snow.

Then the failure shear force is given by

$$
F_{\mathrm{t}}=\frac{M}{r},
$$

and the force normal to the plate equals $F=F_{\mathrm{t}} / \sin \vartheta$. Let $L$ be the length of the plate, then the contact area between snow and plate is given by $A=L e / \sin \vartheta$ and, consequently, the contact stress is

$$
p=\frac{F}{A}=\frac{F_{\mathrm{t}}}{L e} \text {. }
$$

The measurement gives the stress when snow fails to withstand the applied load. The stress of a vertical plate tangential to the snow surface is

$$
S_{\mathrm{f}}=\frac{F_{\mathrm{t}}}{L e} .
$$

We call $S_{\mathrm{f}}$ the failure shear stress of snow. In the simulation, Eqn (9) is used to calculate the load, $F_{\mathrm{t}}$, when shearing starts.

We do not investigate the dynamic shear strength when the movement is continued. In the dynamic case, machining theory is applied (eqn (10) of Brown, 2009, or Shaw, 1984). In machining, the cutting force depends on the edge angle, i.e.

$$
\frac{F_{\mathrm{t}}}{L e}=S \cdot 2 \cot \left(\frac{\vartheta-\beta}{2}\right),
$$

with $S$ the dynamic shear strength of snow. Here $\beta$ determines the friction transverse to the ski and is given by $\beta=\arctan \mu_{\mathrm{t}}$, with $\mu_{\mathrm{t}}$ the dynamic transverse friction coefficient. Its value is considerably larger than the kinetic friction coefficient. According to machining theory, the snow yields along the shear plane, which is inclined at an angle $(\vartheta-\beta) / 2$ to the snow surface. It should be noted that for a vertical ski tool $\left(\vartheta=90^{\circ}\right)$ and without transverse friction $\left(\beta=0^{\circ}\right)$ it holds that $S_{\mathrm{f}}=2 S$.

\section{Regression analysis}

In the data analysis, linear regression models were fitted to the data. To decide which parameters to use, root-meansquare errors (rmse) were computed. $F$ tests were applied and related $p$ values were computed (Johnson and Wichern, 1992; Stahel, 2000). All calculations were performed in $M A T L A B$ using the function 'regress' to calculate regression fits, confidence intervals and $p$ values.
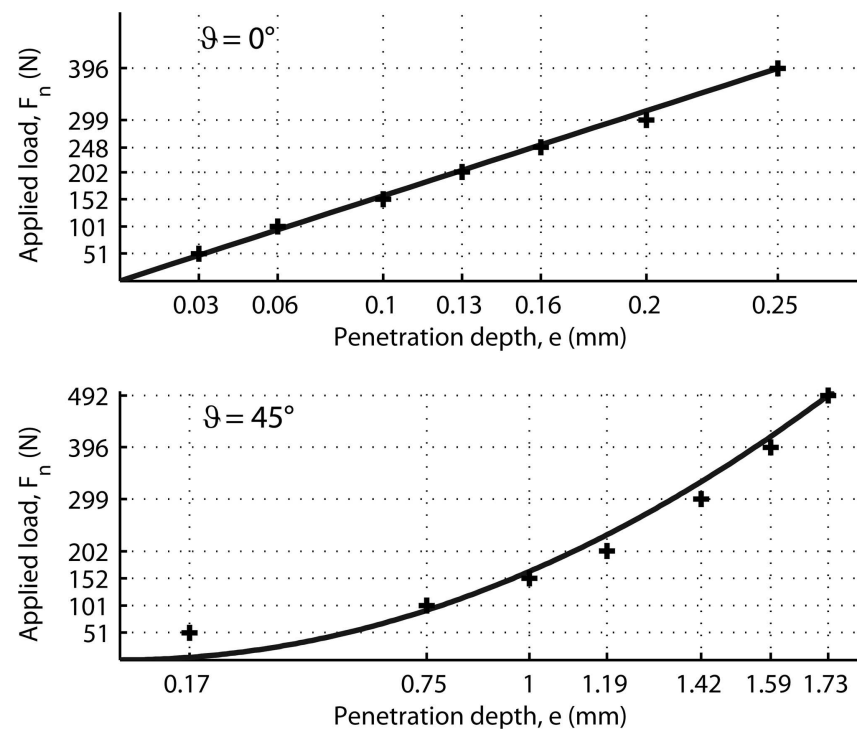

Fig. 5. Penetration force for edge angles of 0 and $45^{\circ}$. e $(\mathrm{mm})$ is the penetration depth of the ski edge and $F_{\mathrm{n}}(\mathrm{N})$ is the applied load. The solid line gives the relation $F_{\mathrm{n}}=H_{V} V$ and the crosses the measured data.

\section{RESULTS}

\section{Snow hardness}

In each penetration experiment, seven force/penetration pairs with increasing load were measured. The observed relation between penetration depth, $e$, and snow reaction force, $F$, increased linearly for the flat ski $(\vartheta=0)$ and nonlinearly for the edged ski $(\vartheta>0)$ (Fig. 5).

Regression fits (Eqn (6)) were computed for linear polynomials, $a$ and $b$, and for the three choices of the snow hardness $\left(H_{\mathrm{e}}, H_{\mathrm{A}}\right.$ and $\left.H_{\mathrm{V}}\right)$. In the case of linear polynomials, $a$ and $b$, the best possible fits had rmse of 140, 58.4 and $53.6 \mathrm{~N}$ for the three types of snow hardness considered. For constant polynomials, $a$ and $b$, the corresponding rmse were $207,75.2$ and $54.8 \mathrm{~N}$. Because of the size of the rmse, the definitions $H_{\mathrm{e}}$ and $H_{\mathrm{A}}$ for the snow hardness were rejected and $H_{\mathrm{V}}$ was accepted. If we further neglect the term $a(\vartheta) A$ (Eqn (5)) then the rmse marginally increases to $53.8 \mathrm{~N}$ for a linear and $54.9 \mathrm{~N}$ for a constant polynomial, $b$. Thus, this term is also rejected. Consequently, we have

$$
F_{\mathrm{n}}=(0.99+0.14 \vartheta) H_{\mathrm{V}} V, \quad \text { rmse }=53.8 \mathrm{~N} .
$$

The units are $\mathrm{N}$ for $F_{\mathrm{n}}$, rad for $\vartheta, \mathrm{N} \mathrm{mm}^{-3}$ for $H_{\mathrm{V}}$, and $\mathrm{mm}^{3}$ for $V$. If we neglect the dependence on the edge angle, $\vartheta$, the rmse of the approximation increases from $53.8 \mathrm{~N}$ to $56.1 \mathrm{~N}$. Thus, we propose:

$$
p(x, y)=H_{\mathrm{v}} \varepsilon(x, y) \quad \text { and } \quad F_{\mathrm{n}}=H_{\mathrm{V}} V,
$$

meaning that the vertical contact stress is proportional to the penetration depth and the snow reaction force is proportional to the displaced volume of snow. The constant of proportionality is given by the snow hardness, $H_{\mathrm{V}}$.

Values for $H_{V}$ ranged from $0.04 \mathrm{~N} \mathrm{~mm}^{-3}$ for fresh snow on ski slopes to $90 \mathrm{~N} \mathrm{~mm}^{-3}$ for late-summer ski slopes on glaciers.

Snow density, $\rho$, and penetrometer hardness, $H_{\mathrm{p}}$, are often referred to as indicators for the stiffness of snow. In our measurements the snow density varied between 420 and $620 \mathrm{~kg} \mathrm{~m}^{-3}$, with a mean value of $556 \mathrm{~kg} \mathrm{~m}^{-3}$. The penetrometer hardness ranged from 7.4 to $21.2 \mathrm{~mm}$ and had a 


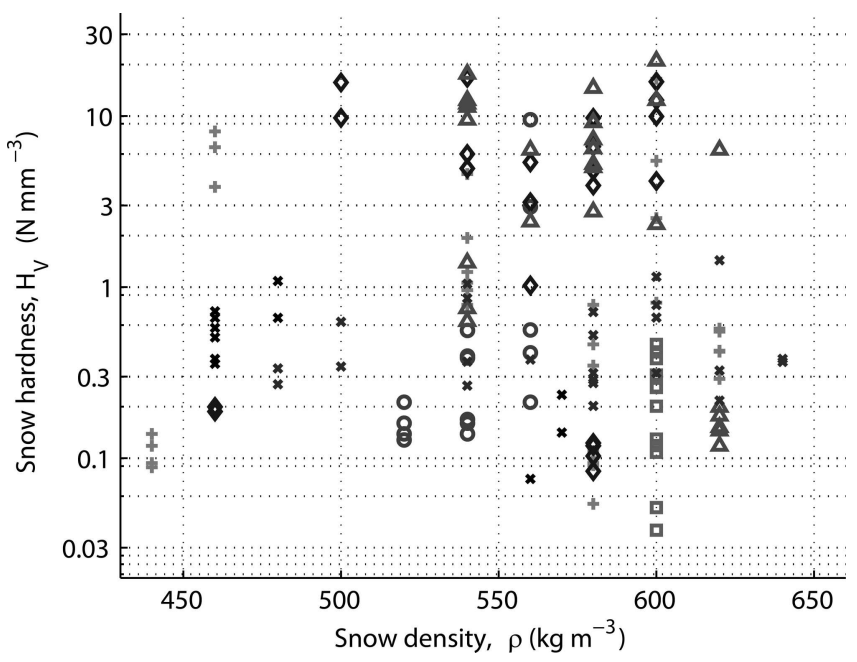

Fig. 6. Snow hardness, $H_{\mathrm{V}}\left(\mathrm{N} \mathrm{mm}^{-3}\right)$, vs snow density, $\rho\left(\mathrm{kg} \mathrm{m}^{-3}\right)$. The different symbols show measurements at different ski resorts.

mean value of $13.6 \mathrm{~mm}$. We tried to establish relations between snow density, $\rho$, or penetrometer hardness, $H_{p}$, and the snow hardness, $H_{V}$, but both relations were statistically insignificant for any reasonable level ( $p$ values 0.99 and 0.83). In Figure 6 we show the data as $H_{\mathrm{V}}$ vs $\rho$.

\section{Failure shear stress}

All our measurements of the failure shear force, $F_{\mathrm{t}}$, are shown in Figure 7. Because torque was applied manually, it was difficult to accomplish measurements for stiff snow and large penetration depths. Thus, the upper right part of the graph is empty. Consequently, we were unable to establish a relation between $e$ and $F_{\mathrm{t}}$ or $S_{\mathrm{f}}$.

To reveal a dependency of the failure shear stress, $S_{\mathrm{f}}$ $\left(\mathrm{N} \mathrm{mm}^{-2}\right)$, on the edge angle, $\vartheta(\mathrm{rad})$, measurements were made at two ski resorts ( $\triangle$ and $\square$ in Figs 7 and 8). For hard snow $(\square)$, no relation was established $(n=20, p$ value $0.50)$, whereas for the soft snow a significant relation was found $(n=30, p$ value $<0.01)$ :

$$
S_{\mathrm{f}}=0.059 \cdot(1-0.266 \vartheta) \quad \text { rmse }=0.006 .
$$

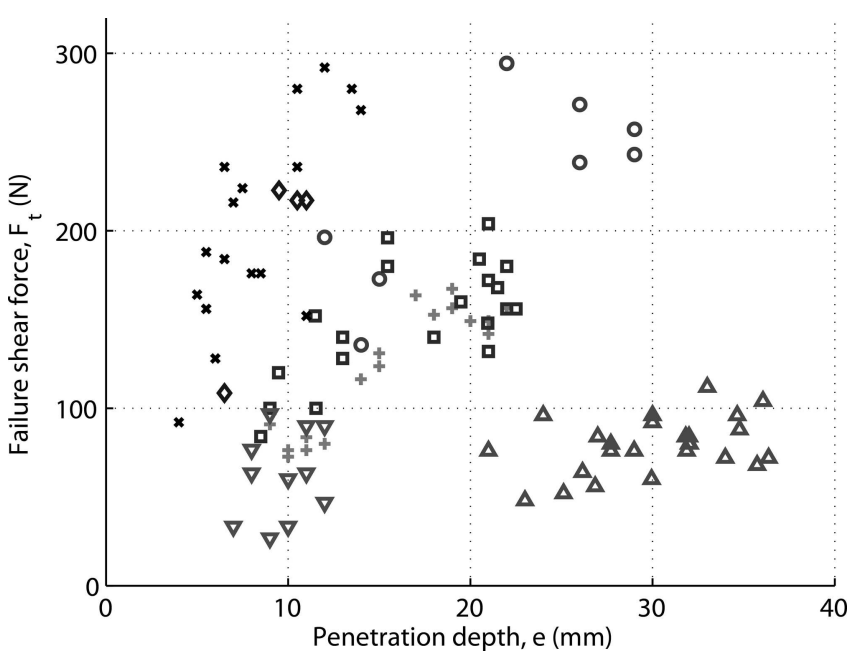

Fig. 7. Failure shear force of snow, $F_{\mathrm{t}}(\mathrm{N})$, vs penetration depth, $e$ $(\mathrm{mm})$. The different symbols refer to measurements at different ski resorts. The edge angle of the blade was $90^{\circ}$, except at two sites $(\triangle$ and $\square$ ), at which the edge angle was systematically varied.

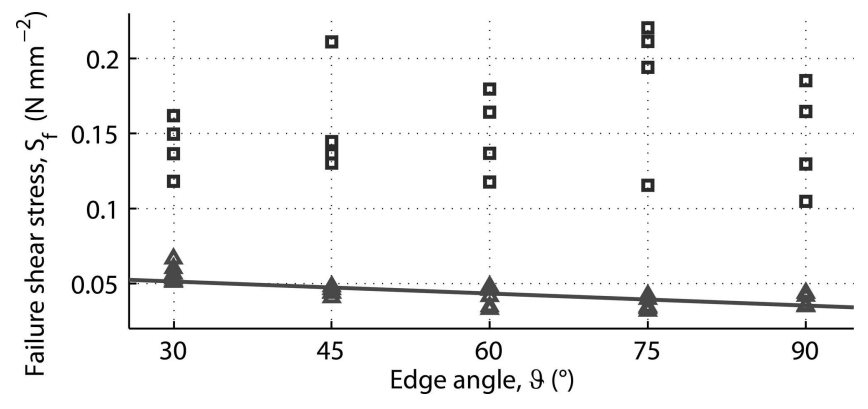

Fig. 8. Failure shear stress of snow, $S_{\mathrm{f}}\left(\mathrm{N} \mathrm{mm}^{-2}\right)$, vs edge angle, $\vartheta\left(^{\circ}\right)$. Data measured at two ski resorts are shown. The dataset for the soft snow $(\triangle)$ significantly depended on the edge angle, thus the regression line is shown.

In Figure 9 the shear measurements for the soft snow are compared with the prediction from machining theory (Eqn (10)). Without transverse friction, i.e. $\beta=0$, the measured data agree with Eqn (10) for an edge angle of $\vartheta=90^{\circ}$. For decreasing edge angles, machining predicts a much faster increase of the tangential reaction stress than the data show. The variation of the measured data is much smaller than the increase predicted by machining. The situation is even worse if one considers a nonzero transverse friction coefficient.

Values for the failure shear stress, $S_{\mathrm{f}}$, ranged from $0.04 \mathrm{~N} \mathrm{~mm}^{-2}$ for fresh snow on ski slopes to $0.30 \mathrm{~N} \mathrm{~mm}^{-2}$ for late-summer ski slopes on glaciers. On slopes prepared for World Cup races, values up to $0.40 \mathrm{~N} \mathrm{~mm}^{-2}$ were observed.

For the penetration experiments, snow density, $\rho$, and penetrometer hardness, $H_{p}$, were measured. The snow density varied between 420 and $740 \mathrm{~kg} \mathrm{~m}^{-3}$, with a mean of $563 \mathrm{~kg} \mathrm{~m}^{-3}$. The penetrometer hardness ranged from 8.0 to $47.0 \mathrm{~mm}$, with a mean of $24.8 \mathrm{~mm}$. A significant relation between snow density, $\rho$, and failure shear stress, $S_{\mathrm{f}}$, was found ( $p$ value $<0.01$ ):

$$
S_{\mathrm{f}}=-0.047+0.00031 \cdot \rho \quad \text { rmse }=0.059 .
$$

It should be noted that the rmse of the approximation is quite large. In Figure 10 the relation between $\rho$ and $S_{\mathrm{f}}$ is shown.

\section{Snow hardness vs failure shear stress}

In a final step the snow hardness, $H_{V}$, and failure shear stress, $S_{\mathrm{f}}$, were measured at two ski resorts at the same time

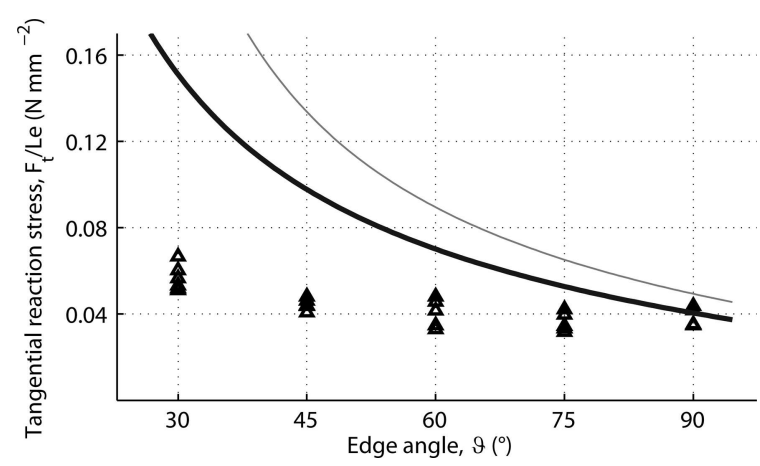

Fig. 9. Tangential snow reaction stress, $F_{\mathrm{t}} / \mathrm{Le}\left(\mathrm{N} \mathrm{mm}^{-2}\right)$, vs edge angle, $\vartheta\left(^{\circ}\right)$. The $\triangle$ symbols show the data for the soft snow, and the solid curves give the prediction due to machining (Eqn (10)). The thick curve refers to machining without transverse friction $\left(\beta=0^{\circ}\right)$ and the thin curve gives the case for $\beta=\arctan (0.2)$. 


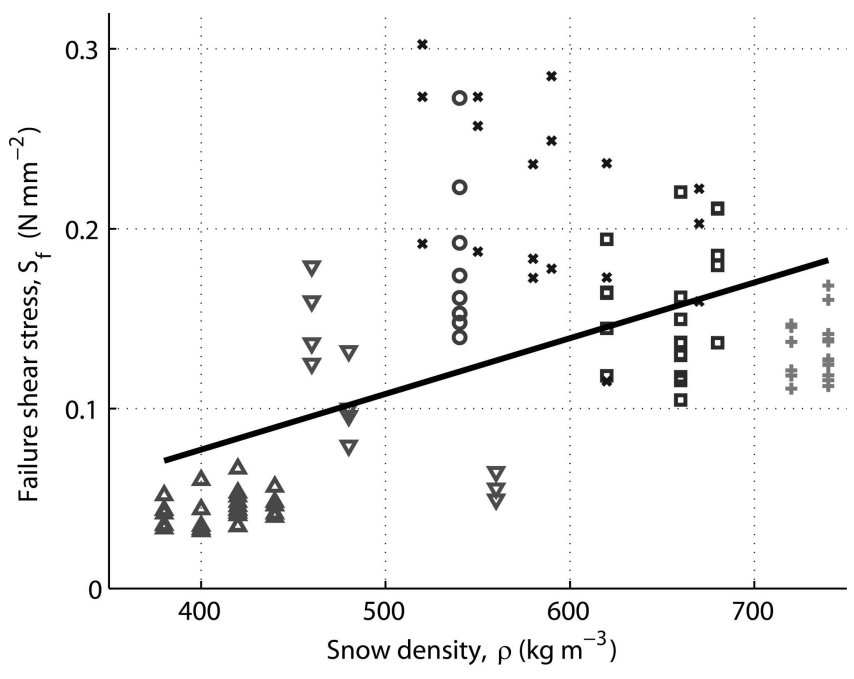

Fig. 10. Failure shear stress of snow, $S_{\mathrm{f}}\left(\mathrm{N} \mathrm{mm}^{-2}\right)$, vs snow density, $\rho$ $\left(\mathrm{kg} \mathrm{m}^{-3}\right)$. The various symbols refer to measurements at different ski resorts. The solid line is the regression line (Eqn (14)).

and location. No significant relation between these variables was found ( $n=35, p$ value 0.52 ). The data are shown in Figure 11.

\section{DISCUSSION}

\section{Simulation of skiing}

The presented study led to models for the penetration and initial shear force of snow, which can be used in forward dynamic simulations of skiing. The penetration force normal to the snow surface is given by $F_{\mathrm{n}}=H_{\mathrm{V}} V(\operatorname{Eqn}(12))$. That is, penetration force is proportional to the volume of snow, $V$, displaced by the ski. The reaction force, $F_{\mathrm{n}}$, can equivalently be formulated for the vertical component of the snow reaction stress, $p_{\mathrm{n}}=H_{\mathrm{v}} \varepsilon_{\text {, }}$ which is actually the variable implemented in a simulation program. The initial force against shearing, $F_{\mathrm{t}}=S_{\mathrm{f}} e \mathrm{~L}$, is proportional to the vertical cross section of the ski, eL. Its implementation is based on the tangential stress exerted by the snow, $p_{\mathrm{t}}=S_{\mathrm{f}}$ or $p_{\mathrm{t}}=0$, depending on whether the ski is shearing or not. The constants of proportionality, snow hardness, $H_{V}$, and failure shear stress, $S_{\mathrm{f}}$, are material parameters of snow. In a simulation of ski turns, the forces between skis and snow depend on the snow properties. Because there exist countless types of snow, these properties are difficult to classify. In a first modeling approach, the parameters snow hardness, $H_{V}$, failure shear stress of snow, $S_{\mathrm{f}}$, and coefficient of kinetic friction, $\mu$, are sufficient to describe the mechanical interaction between the ski and snow. The first two parameters, $H_{V}$ and $S_{f}$, can be assessed at quite low costs in field experiments. This was done in a study for a sledge on two skis performing single turns (Mössner and others, 2013). The snow parameters were measured with the same devices as in this study. A velocity-dependent friction coefficient was determined by parameter identification. Further, a hypoplastic force penetration relation was used. For evaluation the deviation between simulated trajectories and experimental track data was computed. In single turns of 67 and $42 \mathrm{~m}$ length with giant slalom and carver skis, maximum deviations were 0.44 and $0.14 \mathrm{~m}$, respectively, i.e. deviations were $<1 \%$.

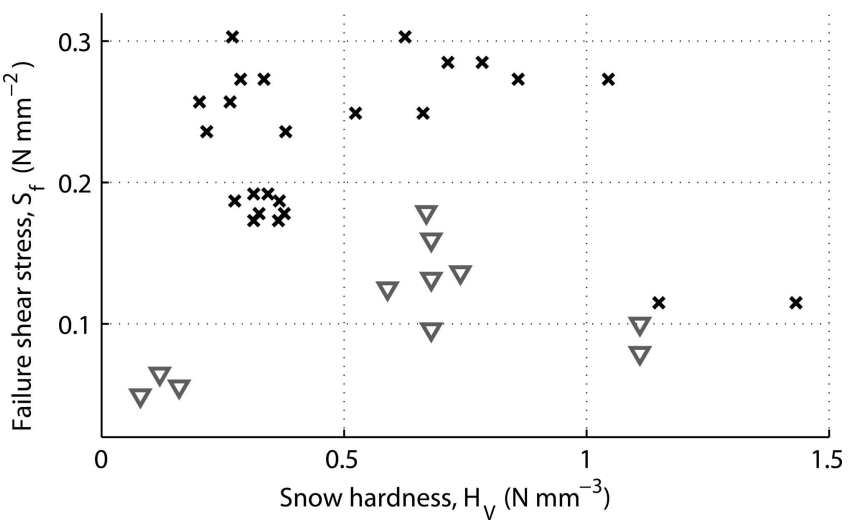

Fig. 11. Failure shear stress of snow, $S_{\mathrm{f}}\left(\mathrm{N} \mathrm{mm}^{-2}\right)$, vs snow hardness, $H_{\mathrm{V}}\left(\mathrm{N} \mathrm{mm}^{-3}\right)$. The different symbols refer to data from two ski resorts.

If snow data are not available, the snow parameters can be estimated. A selection of the snow hardness, $H_{V}$, leads to a certain depth of the ski edge in the simulation, which can be compared with the depth of the track of the skier. In the same way, the selection of the failure shear stress, $S_{\mathrm{f}}$, leads to some amount of skidding and, consequently, determines the turn radius and the width of the track. Because track depth and width, as well as turn radius, are accessible at low costs, this allows feasible snow data for simulations in skiing to be estimated.

\section{Snow hardness and failure shear stress}

Portable devices were developed to assess the snow reaction force of compacted snow on groomed ski slopes against penetration and shearing.

The reaction force against penetration was found to be proportional to the displaced volume of snow, $V$. A dependency solely on the contact area, $A$, or the penetration depth, e, was rejected. The constant of proportionality, $H_{V}$, gives the resistance of compacted snow against further compression. This result is reasonable. Although snow is not elastic, in most simulation studies linear springs are used to model the snow reaction force (Nordt and others, 1999a,b; Casolo and Lorenzi, 2001). In a uniaxial loading experiment for an elastic rod, Hooke's law predicts a reaction force equal to $F=(E / L) \cdot(A \Delta L)$. Here $E / L$ corresponds to the hardness of the rod and $A \Delta L$ to its volume change. In solids the reaction force originates from (elastic) binding forces to nearby particles. Thus, in homogeneous and isotropic bodies, the reaction force is proportional to the volume change. In mixtures, such as soils or snow, the situation is more complicated. For instance, Brown (1980) investigated the snow reaction forces of the neck bindings between snow grains of sintered snow. Johnson and Schneebeli (1999) modeled the penetration force as $F=N f$ with $N$ the number and $f$ the contribution of each intact microstructural element. Both works support the hypothesis that the snow reaction force against compression is proportional to its volume change.

The initial failure shear force was found to be proportional to the penetration depth, $e$, multiplied by the length of the tool, $L$. The constant of proportionality, $S_{f}$, is given by the failure shear stress of snow. $S_{\mathrm{f}}$ is different to the shear modulus of snow, $S$; it describes snow failure and not elastic deformation. In our measurements it was not verified that the failure shear stress depends on the edge angle. For hard 
snow the data were insignificant. For soft snow just a small decrease was found.

The snow measurements of Federolf and others (2006) differ in various respects. They measure the snow reaction force normal to the ski base, whereas we measured the components normal and parallel to the undisturbed snow surface. Thus, their data have to be interpreted as a mixture of snow compression and shearing. They report a mean value for the reaction pressure of $p^{\text {mean }}=A e+B$ along the contact surface of the ski base. The contact area equals $e L / \sin \vartheta$. Therefore the snow reaction force is

$$
F=A e^{2} L / \sin \vartheta+B e L / \sin \vartheta
$$

acting normal to the ski base. Our models predict a force normal to the ski base of

$$
F=F_{\mathrm{n}} \cos \vartheta+F_{\mathrm{t}} \sin \vartheta=H_{\mathrm{V}} \frac{e^{2} L \cos \vartheta}{2 \tan \vartheta}+S_{\mathrm{f}} e L \sin \vartheta .
$$

Thus we have $A=H_{\mathrm{V}} \cos ^{2} \vartheta / 2$ and $B=S_{\mathrm{f}} \sin ^{2} \vartheta$. Federolf and others (2006, their fig. 9) report values of $A=$ $0.034,0.026$ and $0.0036 \mathrm{~N} \mathrm{~mm}^{-3}$ and $B=0.35,0.058$ and $0.063 \mathrm{~N} \mathrm{~mm}^{-2}$ for a well-prepared race piste, a compact recreational piste and spring snow, respectively. The corresponding values for $H_{\mathrm{V}}$ are $0.21,0.16$ and $0.022 \mathrm{~N} \mathrm{~mm}^{-3}$ and for $S_{\mathrm{f}}$ are $0.52,0.086$ and $0.094 \mathrm{~N} \mathrm{~mm}^{-2}$, respectively. These values agree well with our data.

Because snow density and penetrometer hardness are available at low costs, they are used to parameterize data on snow. We tried to find a relation between these quantities and the snow hardness, $H_{V}$, or the failure shear stress of snow, $S_{\mathrm{f}}$. We found a statistically significant relation between snow density, $\rho$, and failure shear stress, $S_{\mathrm{f}}$. However, the rmse for this relation was quite large. No statistically significant relation between failure shear stress, $S_{\mathrm{f}}$, and snow hardness, $H_{V}$, was obtained. Domine and others (2011, their fig. 3) gave a relation between the failure shear stress of snow and the snow density: $S_{\mathrm{f}}=(0.1027 \rho-11.5323)^{2}$. Here $S_{\mathrm{f}}$ is given in Pa and $\rho$ in $\mathrm{kg} \mathrm{m}^{-3}$. For a snow density of $500 \mathrm{~kg} \mathrm{~m}^{-3}$ this relation predicts a failure shear stress of $0.0015 \mathrm{~N} \mathrm{~mm}^{-2}$, while our relation (Eqn (14)) gives $0.11 \mathrm{~N} \mathrm{~mm}^{-2}$. We believe this difference arises because we investigated compacted snow of ski slopes, while Domine and others (2011) investigated natural packed snow.

\section{Limitations}

Snow is a mixture of ice crystals, water and enclosed air. During grooming on ski slopes, snow is compacted and homogenized. Due to daily temperature variations the particles of this conglomerate sinter together. Therefore the snow surface is usually flat and snow properties are, with respect to the size of a ski, reasonably constant. However, during experiments with tools, as in this work, small-scale variations in the snow properties can be observed. Along the slope, snow conditions vary due to ambient conditions and preparation. A further problem arises from the fact that snow measurements have do be done on a flat surface near the slope where the field experiments are performed. There the slope is inclined and, thus, especially on sunny parts of the slope, solar radiation is more effective. Consequently, snow conditions might be harder at the measurement site than at the skiing experiment site.

The simplicity of the devices restricts the achievable accuracy. The presented devices are good at obtaining basic snow data occurring in field experiments. To investigate further details, measurements in controlled laboratory settings are necessary. The authors have access to a linear tribometer (Centre of Technology of Ski and Alpine Sport, Innsbruck). There, after some adaptations, shear experiments with prescribed penetration depth, shear velocity and edge angle can be performed. This affords a unique opportunity to improve upon the limited knowledge that exists on the shear process of snow.

A second-order term for the penetration force was found: $F_{\mathrm{n}}=(1+0.14 \vartheta) H_{\mathrm{V}} V($ Eqn (11)). This term suggests a small increase of the reaction force for increased edge angles. For the same applied load, the penetration depth of the refined model is smaller than for the proposed model: $F_{\mathrm{n}}=H_{\mathrm{V}} \mathrm{V}$ (Eqn (12)). However, cutting effects introduced by the ski edge reduce the reaction force and cause a larger penetration depth. Because the improvement in the rmse was only $4 \%$, it is questionable whether this effect is real. In addition, in our simulation of skiing we observed that computing the penetration force either by Eqn (11) or (12) resulted in qualitatively similar simulated trajectories.

The material parameters of snow presented in this study allow a first modeling approach for the snow contact forces needed in the simulation of skiing. Both the penetration and the shear force are measured in static experiments. Velocitydependent effects, such as the dynamic shear force or snow damping for the penetration force, have to be investigated. At present, the coefficient of kinetic friction can only be determined by theoretical investigations and laboratory measurements (Colbeck, 1992; Baürle and others, 2007) or by inverse techniques, such as parameter identification (Kaps and others, 1996; Sahashi and Ichino, 1998). Further, it should be considered that snow is not elastic. Deformations of the snow surface made by the ski remain. Such effects can be modeled by a hypoplastic model for the penetration force. The steepness of the unloading/reloading branch of the hypoplastic relation has been determined (Mössner and others, 2013, and references therein).

Due to machining theory (Shaw, 1984; Brown, 2009, eqn (10)) the shear force depends on the edge angle. In our study we could not verify this effect for the failure shear force. Machining is applied and was verified in various cases of metal cutting, but few data are available for snow or ice. Brown and Outwater (1989) performed experiments on snow that was considerably softer than the softest snow of our study and explained their results by classical machining. Prior to that, Lieu and Mote (1985) and, later, Tada and Hirano (1999) carried out cutting experiments on ice. Their results were formulated as regression equations that differ from the predictions of machining. The dependence of the tangential shear force of snow requires further investigation, both experimental and theoretical. Possibly machining can be extended to fit the requirements of snow on groomed ski slopes.

The failure shear stress of snow is important for the simulation of skiing. It determines the transition between carving and skidding. In well-carved ski turns it is common that parts of the skis are skidding. We have no experimental data when the whole ski is skidding. Then considerations may need to switch from the failure shear stress to the dynamic shear strength. It is presumed that the dynamic shear strength is smaller than the failure shear stress. As long as well-carved situations are investigated, simulation results are in good agreement with measured track data (Mössner and others, 2013). However, whether this is correct in skidded turns is beyond the present work. 


\section{CONCLUSIONS}

The parameters snow hardness, $H_{V}$, and failure shear stress of snow, $S_{\mathrm{f}}$, were measured on groomed ski slopes. Models were derived for the snow reaction forces. The reaction force against penetration is given by $F_{\mathrm{n}}=H_{V} V$, with $V$ the volume of snow displaced by the ski. The failure shear force tangential to the snow surface is given by $F_{\mathrm{t}}=S_{\mathrm{f}} \mathrm{eL}$, with $e L$ the vertical cross section of the ski. The models were successfully evaluated by comparing simulated trajectories with experimental track data (Mössner and others, 2013). Maximum deviations between computed and real trajectories were $<1 \%$ of the overall length of the runs.

\section{ACKNOWLEDGEMENT}

This investigation was supported by HTM Tyrolia.

\section{REFERENCES}

Bäurle L, Kaempfer TU, Szabó D and Spencer ND (2007) Sliding friction of polyethylene on snow and ice: contact area and modeling. Cold Reg. Sci. Technol., 47(3), 276-289 (doi: 10.1016/j.coldregions.2006.10.005)

Brown CA (2009) Modeling edge-snow interactions using machining theory. In Müller E, Lindinger S and Stöggl Teds. Science and skiing IV. Meyer \& Meyer Sport (UK), Maidenhead, 175-182

Brown CA and Outwater JO (1989) On the skiability of snow. In Johnson RJ, Mote CD Jr and Binet MH eds. Skiing trauma and safety: 7th International Symposium. (ASTM Special Technical Publication 1022-EB) American Society for Testing and Materials, West Conshohocken, PA, 329-336

Brown RL (1980) A volumetric constitutive law for snow based on a neck growth model. J. Appl. Phys., 51(1), 161-165 (doi: 10.1063/1.327394)

Brun E and Rey L (1987) Field study on snow mechanical proprties with special regard to liquid water content. IAHS Publ. 162 (Symposium at Davos 1986 - Avalanche Formation, Movement and Effects), 183-193

Camponovo C and Schweizer J (2001) Rheological measurements of the viscoelastic properties of snow. Ann. Glaciol., 32, 44-50 (doi: 10.3189/172756401781819148)

Casolo F and Lorenzi V (2001) Relevance of ski mechanical and geometrical properties in carving technique: a dynamic simulation. In Müller E, Schwameder H, Raschner C, Lindinger S and Kornexl E eds. Science and skiing II. Proceedings of the 2nd International Conference on Skiing and Science, 9-15 January 2000, St Chrisoph a. Arlberg, Austria. (Schriften zur Sportwissenschaft Band 26) Verlag Dr Kovăc, Hamburg, 165-179

Colbeck SC (1992) A review of the processes that control snow friction. CRREL Monogr. 92-2

Conger SM and McClung DM (2009) Comparison of density cutters for snow profile observations. J. Glaciol., 55(189), 163-169 (doi: 10.3189/002214309788609038)

Domine F, Bock J, Morin S and Giraud G (2011) Linking the effective thermal conductivity of snow to its shear strength and density. J. Geophys. Res., 116(F4), F04027 (doi: 10.1029/ 2011JF002000)

Federolf $\mathrm{P}$, JeanRichard F, Fauve M, Lüthi A, Rhyner H-U and Dual J (2006) Deformation of snow during a carved ski turn. Cold Reg. Sci. Technol., 46(1), 69-77 (doi: 10.1016/j.coldregions.2006. 06.006)

Federolf P, Roos M, Lüthi A and Dual J (2010a) Finite element simulation of the ski-snow interaction of an alpine ski in a carved turn. Sports Eng., 12(3), 123-133 (doi: 10.1007/s12283010-0038-z)
Federolf P, Lüthi A, Roos M and Dual J (2010b) Parameter study using a finite element simulation of a carving Alpine ski to investigate the turn radius and its dependence on edging angle, load, and snow properties. Sports Eng., 12(3), 135-141 (doi: 10.1007/s12283-010-0039-y)

Fierz C and 8 others (2009) The international classification for seasonal snow on the ground. (IHP Technical Documents in Hydrology 83) UNESCO-International Hydrological Programme, Paris

Gill PE, Murray W and Wright MH (1995) Pratical optimization. Academic Press, London

Hirano Y and Tada N (1996) Numerical simulation of a turning alpine ski during recreational skiing. Med. Sci. Sports Exercise, 28(9), 1209-1213

Johnson JB and Schneebeli M (1999) Characterizing the microstructural and micromechanical properties of snow. Cold Reg. Sci. Technol., 30(1-3), 91-100 (doi: 10.1016/S0165-232X(99) 00013-0)

Johnson RA and Wichern DW (1992) Applied multivariate statistical analysis, 3rd edn. Prentice Hall, Englewood Cliffs, NJ

Kaps P, Nachbauer W and Mössner M (1996) Determination of kinetic friction and drag area in alpine skiing. In Mote CD Jr, Johnson RJ, Hauser W and Schaff PS eds. Skiing trauma and safety: 10th Volume. (ASTM Special Technical Publication 1266-EB) American Society for Testing and Materials, West Conshohocken, PA, 165-177

Lieu DK and Mote CD Jr (1984) Experiments in the machining of ice at negative rake angles. J. Glaciol., 30(104), 77-81

Lieu DK and Mote CD Jr (1985) Mechanics of the turning snow ski. In Johnson RJ and Mote CD Jr eds. Skiing trauma and safety: 5th International Symposium. (ASTM Special Technical Publication 860-EB) American Society for Testing and Materials, West Conshohocken, PA, 117-140

Mellor M (1975) A review of basic snow mechanics. IAHS Publ. 114 (Symposium at Grindelwald 1974 - Snow Mechanics), 251-291

Mote $C$ and Renshaw A (1991) A model for the turning snow ski. In Mote CD, Johnson RJ, Hauser W and Schaff PS eds. Skiing trauma and safety: 8th International Symposium. (ASTM Special Technical Publication 1104-EB) American Society for Testing and Materials, West Conshohocken, PA

Mössner M, Heinrich D, Kaps P, Schretter H and Nachbauer W (2009) Effects of ski stiffness in a sequence of ski turns. In Müller E, Lindinger S and Stöggl T eds. Science and skiing IV. Meyer \& Meyer Sport (UK), Maidenhead, 374-388

Mössner M, Heinrich D, Schindelwig K, Kaps P, Schretter H and Nachbauer W (2013) Modeling the ski-snow contact in skiing turns using a hypoplastic vs an elastic force-penetration relation. Scand. J. Med. Sci. Sports (doi: 10.1111/sms.12035)

Nachbauer W, Schröcksnadel P and Lackinger B (1996) Effects of snow and air conditions on ski friction. In Mote CD, Johnson RJ, Hauser W and Schaff PS eds. Skiing trauma and safety: 10th Volume. (ASTM Special Technical Publication 1266-EB) American Society for Testing and Materials, West Conshohocken, PA, 178-185

Nakamura T, Abe O, Hashimoto R and Ohta T (2010) A dynamic method to measure the shear strength of snow. J. Glaciol., 56(196), 333-338 (doi: 10.3189/002214310791968502)

Nordt AA, Springer GS and Kollár LP (1999a) Computing the mechanical properties of alpine skis. Sports Eng., 2(2), 65-84 (doi: 10.1046/j.1460-2687.1999.00026.x)

Nordt AA, Springer GS and Kollár LP (1999b) Simulation of a turn on alpine skis. Sports Eng., 2(3), 181-199 (doi: 10.1046/j.14602687.1999.00027.x)

Sahashi T and Ichino S (1998) Coefficient of kinetic friction of snow skis during turning descents. Jpn J. Appl. Phys., 37(1 No. 2), 720-727 (doi: 10.1143/JJAP.37.720)

Shapiro LH, Johnson JB, Sturm M and Blaisdell GL (1997) Snow mechanics: review of the state of knowledge and applications. CRREL Rep. 97-3 
Shaw MC (1984) Metal cutting principles. Oxford University Press, New York

Stahel WA (2000) Statistische Datenanalyse: eine Einführung für Naturwissenschaftler. Vieweg, Wiesbaden

Tada $N$ and Hirano $Y$ (1999) Simulation of a turning ski using ice cutting data. Sports Eng., 2(1), 55-64 (doi: 10.1046/ j.1460-2687.1999.00020.x)
Tada $N$ and Hirano $Y$ (2002) In search of the mechanics of a turning alpine ski using snow cutting force measurements. Sports Eng., 5(1), 15-22 (doi: 10.1046/j.1460-2687. 2002.00092.x)

Theile T, Szabo D, Luthi A, Rhyner H and Schneebeli M (2009) Mechanics of the ski-snow contact. Tribol. Lett., 36(3), 223-231 (doi: 10.1007/s11249-009-9476-9)

MS received 8 February 2013 and accepted in revised form 14 September 2013 